\title{
Class-ificações Mediadas: Representações de classe e cultura na televisão britânica contemporânea
} Mediated class-ifications: Representations of class

\section{RESUMO}

Este artigo se inicia com os recentes debates sobre a representação da vida da classe trabalhadora, especialmente a vida dos pobres displicentes, em programas de televisãorealidade no Reino Unido. Estas questões são contextualizadas em amplos e diversificados debates históricos sobre: a) a categoria de classe como um modo de determinação social (e como um modelo explanatório), b) as relações entre linguagem, classe e cultura na sociologia educacional e em publicações comunitárias e, c) em relação à clássica teorização marxista sobre a classe trabalhadora respeitável e o lumpemproletariado. $\mathrm{O}$ artigo finaliza com uma consideração sobre os debates da representação da classe trabalhadora na série dramática contemporânea da TV britânica, Shameless ${ }^{1}$.

* Professor no

Departamento de Mídia e Comunicação no Goldsmiths College, University of London.

1. "Sem-vergonhas".

Palavras-chave: consciência de classe, cultura, linguagem, lumpemproletariado, televisão-realidade

\begin{abstract}
This article takes, as its point of departure, recent debates about the representation of working-class life, especially the lives of the feckless poor, on reality television in the UK. These issues are contextualized by reference to a set of wider-ranging historical debates about: a) the category of class as a mode of social determination (and as an explanatory model); b) the relations of language, class and culture in educational sociology and in community publishing; and, c) in relation to classical Marxism's theorization of both the respectable working class and the lumpen proletariat. The article concludes with a consideration of debates about the representation of the working class in the contemporary British TV drama series Shameless.
\end{abstract}

Keywords: class consciousness, culture, language, lumpen proletariat, reality television 


\section{INTRODUÇÃO}

OS ÚLTIMOS ANOS, a terminologia de classe tem sido excluída da mídia e dos estudos culturais, em parte, ao que parece, em resposta às críticas pós-estruturalistas de "reducionismo" e "essencialismo" na utilização de categorias sociais como elementos explanatórios em análises culturais. No entanto, no Reino Unido, tem havido um engajamento contínuo por parte de uma pequena minoria de estudiosos acadêmicos com a questão de classe (Medhurst, 2000; Munt, 2000; Skeggs, 1997, 2004), e alguns trabalhos recentes focando a representação de classe na TV popular e na televisão-realidade (reality TV) estão agora voltando a discutir esse tema (Biressi e Nunn, 2005, 2008; Skeggs et al. 2008; Madeira e Skeggs, 2008). Eu pretendo utilizar essas últimas referências como um tema-chave na tentativa de relacionar os debates contemporâneos sobre a representação na televisão popular em um conjunto mais amplo de questões históricas e teóricas sobre classe, cultura, estilo de vida, linguagem e política.

O trocadilho no meu título, "class-ificação" aponta para duas direções. Em primeiro lugar, está relacionado ao que acontece quando um determinado conjunto de indivíduos é classificado, por outros, como "pertencendo" de alguma forma (tanto analiticamente ou valorativamente) a um grupo, como quando seus estilos de vida são classificados como patológicos. Em segundo lugar, está relacionado às consequências dos indivíduos quando se autocategorizam - ou, mesmo, falham ao (ou se recusam a) fazê-lo - como membros de uma classe em particular. Eu sempre tive uma relação ambivalente com o famoso argumento de Raymond Williams de que "não há massas, só maneiras de falar sobre as outras pessoas como massas". Se substituirmos classes por massas nessa sentença, penso que muitas vezes existem boas razões para falar de pessoas como membros de classes. Isso é especialmente verdade porque, contrariamente às afirmações das teorias de Ulrich Beck de "individualização" (Beck e BeckGernsheim, 2002), as classes ainda são instituições sociais muito poderosas. Certamente, no Reino Unido, todas as evidências apontam para o fato de que as taxas de mobilidade intergeracionais estão, na melhor das hipóteses, estáveis, se não diminuindo. Assim, a posição da classe ao nascer ainda é um indicador muito poderoso do provável status social de uma pessoa na sua vida adulta. ${ }^{2}$

\section{AUDIÊNCIA TELEVISIVA, CULTURAS DE CLASSE}

\section{TRABALHADORA E O CÃO (MARXISTA) QUE PAROU DE LATIR}

Se os indivíduos da classe trabalhadora têm sido cada vez mais visíveis nas telas de televisão britânica nos últimos anos, isso aconteceu principalmente pelo gênero cada vez mais popular de televisão-realidade que os representa de maneira intensiva. Hoje em dia, ouvimos muitas vezes que esse gênero é vital para o futuro da própria TV. No entanto, aqui como em outra parte, devemo também ter em mente a afirmação de Lynn Spigel, de que quanto mais falamos de futurologia, mais precisamos colocar os assuntos em perspectiva histórica (Spigel, 2004). A questão, claro, é como fazer isso e, mais especificamente, a quais histórias gerais o fenômeno da televisão-realidade pertence e para quai aspectos da televisão-realidade essas histórias são mais relevantes. À luz dessas considerações, o meu objetivo aqui é posicionar esse gênero (que eu considero envolver não só um modo particular de programação, mas que considero também caracterizar-se por sua tendência a representar determinadas categoria de pessoas) no contexto de várias histórias diferentes. Meu desejo é que esta perspectiva em longo prazo, ao relativizar o foco contemporâneo, sirva, pela mesma razão, para esclarecer o significado político mais amplo daquilo que poderia parecer meramente debates especializados sobre um gênero particular (se popular) de televisão.

O primeiro contexto histórico, e familiar para a maioria dos leitores desta publicação, está relacionado aos debates sobre essencialismo de classe na pesquisa de audiência da mídia. O segundo refere-se aos primeiros debates de sociologia educacional sobre classe, linguagem, poder e privação cultural (conferir Bernstein, 1971; Rosen, 1972) e suas implicações para o trabalho contínuo de organizações como a Federation of Worker Writers and Community Publishers (ver Morley e Worpole, 1982; Worpole, 2008). Esse debate em particular pode ser importante para iluminar as críticas contemporâneas da representação ( possível exploração) das pessoas da classe trabalhadora em televisão-realidade. Uma questão que gostaria de destacar diz respeito ao fato de que a força dessas críticas depende necessariamente de uma posição implícita, mas raramente explicada, sobre o que constituiria uma maneira boa, desejável ou adequada de representação da classe trabalhadora. Há ainda a questão de quem seria qualificado para decidir essa questão - apenas as pessoas representadas em si? Aqueles com histórico de uma classe similar? Seus representantes políticos? Algum grupo particular de especialistas? Neste ensaio, mesmo de forma preliminar, quero tentar colocar em discussão algumas dessas questões espinhosas, muitas das quais têm as suas raízes em debates anteriores.

$\mathrm{O}$ terceiro contexto histórico refere-se às teorias marxistas de classe e, em particular, às formulações de Marx sobre a problemática (e na sua visão, perigosa) categoria do lumpemproletariado. Meu interesse é traçar as relações entre essas questões e os debates contemporâneos sobre a representação da classe destituída britânica, a nação $c h a v^{4}$ na televisão-realidade (doravante TR). Creio que se olharmos para a TR por este prisma, podem ser levantados alguns

\section{3. http://www.fedonline.} rg. uk/fed/index.php.
cesso em 17 abr 2010 (NT) 
paralelos (e transposições) bastante incomuns entre os comentários de Marx sobre a "degeneração" patológica do lumpemproletariado e os discursos "disciplinares" criticando o estilo de vida "insalubre" dos "pobres indignos" na televisão contemporânea. Nesse sentido, também quero levantar algumas questões referentes às limitações das abordagens predominantemente foucaultianas (com foco em questões de governamentalidade e produção de formas específicas de subjetividade), que atualmente proporcionam o vocabulário da principal forma de crítica da TR. Muitas dessas críticas surgem dos influentes estudos de Nikolas Rose (1989) sobre governamentalidade e, portanto, focam o papel da TR em inculcar, entre seu público, uma forma peculiar de "subjetividade empreendedora" (idem). Aqui parecem existir dois problemas principais, sendo que ambos têm até agora, em grande parte, escapado da atenção da crítica.

O primeiro problema refere-se às limitações do funcionalismo embutido nesse tipo de terminologia foucaultiana. ${ }^{5} \mathrm{Em}$ muitos aspectos, é difícil perceber a diferença entre um modelo que presume o sucesso automático de uma forma particular de governamentalidade na produção de um modo particular de subjetividade (o eu empreendedor) e as teorias há muito tempo desacreditadas de Talcott Parsons sobre os efeitos automáticos de "socialização" na reprodução de determinados tipos de indivíduos "requeridos" para o sucesso de um dado sistema social (Parsons, 1964). O mesmo problema também danifica as formas mais cruas das teorizações marxistas que assumem uma bem-sucedida imposição das ideologias dominantes. Não há espaço conceitual em nenhum desses modelos para qualquer autonomia de resposta (crítica ou não) por parte das pessoas que consomem (ou são interpeladas ou sujeitas a) esses discursos, cujos efeitos automáticos são simplesmente presumidos. O outro problema é que alguns comentadores contemporâneos parecem escrever como se imaginassem ser possível produzir alguma forma de discurso (sem juízo de valor?), que não tenta moldar a subjetividade de maneira alguma (ver Fish, 1989). Nessa medida, não é claro se esses críticos têm uma objeção utópica para a formação da subjetividade em si, ou para a produção da forma particular de subjetividade que parece ser cultivada pela TR.

\section{TELEVISÃO-REALIDADE: A HISTÓRIA ATÉ AGORA..}

A TR é claramente uma área vital de pesquisa se considerarmos que ela é cada vez mais importante na programação da televisão popular, e, se acreditarmos que uma das coisas que ela faz é melodramatizar todos os destinos, como uma questão de responsabilidade individual, ao mesmo tempo obscurecendo os fatores estruturais que ainda os determinam fortemente. ${ }^{6}$ Isto é especialmente verdade se queremos entender como os discursos econômicos neoliberais são feitos atualmente, não mais - nem menos - do que como senso comum e, como sabemos, a construção do senso comum (e seus limites) é o aspecto crítico de qualquer processo hegemônico.

Como já foi bem estabelecido, a TR é evidentemente essencial para a economia moral de nossa época, em que determinados tipos de pessoas, família e estilos de vida são apresentados como dignos de emulação, enquanto outros são desvalorizados e classificados como patológicos ou disfuncionais. Nesse contexto, Nick Couldry (2008) sugere que cada sistema de crueldade exige o seu próprio teatro. Se a TR é mais percebida como uma das formas teatrai específicas através das quais o sistema do neoliberalismo dramatiza as sua próprias necessidades em indivíduos (principalmente para buscar soluções biográficas para contradições estruturais), então, como ele observa, este não é um desenvolvimento histórico peculiar, mas é melhor compreendido como parte de uma longa série dessas transformações. Como E. P. Thompson apontou muito tempo atrás, "cada mudança na organização econômica exige novas disciplinas, novos incentivos e uma natureza humana nova" (Thompson, 1967: 57). Retornarei mais tarde a este ponto histórico, já que, de certa forma, relativiza a especificidade das nossas preocupações contemporâneas com a produção do mercado neoliberal capitalista de uma forma de subjetividade empreendedora

Recentemente, tanto Couldry (2008) como Christine Geraghty (2006) trouxeram argumentos lukacsianos fora de moda, de que uma das razões pela quais o melodrama e a TR têm sido cada vez mais importantes para a mídia nos últimos tempos é precisamente porque esses gêneros têm um ajuste particula com as estruturas altamente individualizadas do neoliberalismo. O conceito implícito em ambas as análises (embora apenas Couldry se refira a ele diretamente e, mesmo assim, apenas de passagem) é o de ideologia, um termo não muito utilizado atualmente. Talvez agora, ideologia seja simplesmente vista como um objeto ruim do qual os comentaristas contemporâneos estão ansiosos para se distanciar. Mas é um conceito difícil de ignorar ao ler comentários sobre a TR já que a maioria deles é pelo menos tão preocupada com o que os discursos da TR escondem como com o que eles revelam, que é, afinal, a função clássica da ideologia, da maneira que concebia o próprio Marx.

Um elemento de sustentação da crítica da TR diz respeito à psicologização e individualização da responsabilidade de destinos pessoais e familiares. A questão-chave aqui é a maneira pela qual esse discurso obscurece as condiçõe estruturais que, apesar das narrativas de escolha do neoliberalismo, continuam a gerar desigualdade de oportunidades de vida para os que estão fazendo a escolha. Neste processo de transferência de causalidade, no qual os indivíduo são chamados a prestar contas dos seus fracassos que estão muitas vezes fora de representação de classe na televisão. Tenho total TRseienncia de que a própr longa e complexa, que está bem além do que quero transmitir aqui. Gostaria de referir apenas de passagem
que, embora convencionalque, embora convencionalhistória é rastreada até a série Family (1974) de Paul Watson, transmitida pelo Brian Winston (2007) ofereceu uma perspectiva histórica muito mais ampla, que rastreia a $T R$ até seus primeiros ancestrais, como o documentário
Chronique d'un été, de Edgar Morin e Jean Rouch, rodado em Paris em 1960. Com outra direção, ess história também já foi transposta para o universo
da videoarte contemporánea. A exposição feita em 2006 por Gillian Wearing, amily History, reformulou meio de uma entrevista retrospectiva com um dos participantes originais do programa, realizado por uma apresentadora de um
talk show contemporanneo, Trisha Goddard, dentroo do contexto do comentário autorreflexivo do artista sobre sua experiència, durante sua própria infância,
como espectador da série de Watson (Wearing, 2006).

\section{Ver os comentários crí-} ticos de John Corner sobre novos sistemas de análise de discurso "não contribuiram imediatamente pel
sua clareza e poder de persuasão"e posimplesmente persuasa. e simplesmente
substituíram o conceito de ideologia com um esquema conceitual "no qual politica mal aparece"
(Corner, 2004: 11). 
de seu controle, os fatores estruturais (como classe) desaparecem (conferir Palmer, 2004). Após a identificação forense, feita por especialistas, das muitas falhas nos lares de classes trabalhadoras e seus estilos de vida, há uma grande quantidade de trabalho a ser feito sobre os órgãos competentes e as famílias, se procuramos conformidade nos padrões de classe média. Evidentemente, se supomos que a pobreza é simplesmente um resultado de más escolhas, algo que os indivíduos podem evitar ao serem reciclados por conselhos de especialistas e por dicas úteis, tudo o que resta é a implementação bem-sucedida da televisão como um novo meio de comunicação pedagógico de governamentalidade, que promulgaria um novo e apropriado imaginário cultural. Com essa iniciativa, os maus cidadãos serão identificados, envergonhados, e então reformados (ou, pelo menos, eles podem desempenhar uma função valiosa, provendo uma referência negativa contra a qual o bom cidadão pode então medir o seu sucesso ver Biressi e Nunn, 2005, 2008).

\section{OS NOVOS DECLÍNIOS DE CLASSE}

Dessa maneira, somos informados que a TR oferece um conjunto voyeurístico de espetáculos de vergonha, envolvendo a exibição e a exposição das inadequações de pessoas vulgares e seus estilos de vida na forma de um gênero de entretenimento. Como Anita Biressi e Heather Nunn colocam, a questão aqui é "a que custo estas imagens são circuladas [neste] novo declínio de classe" (2008: 15), com foco sobre os corpos não saudáveis, gostos vulgares e estilos de vida disfuncionais dos pobres indisciplinados. Como adequadamente notam esses críticos, esse é um acervo de imagens que pode ser rastreado até a tradição histórica das representações feitas anteriormente por Hogarth das classes destituídas, e que também pode ser comparado a algumas das formas mais cruéis de representação cômica de pobres displicentes/incompetentes, tão popular na televisão britânica contemporânea.

Em todos esses casos, as diferenças de classe se manifestam em diversos modos. Portanto, a pesquisa de Beverley Skeggs, Helen Wood e Nancy Thumin aborda as diferenças de classe em um nível material e simbólico, tanto em relação ao aparelho de televisão como um objeto simbólico, como em relação aos discursos que este objeto articula. Neste momento poderia ser útil explorar ainda mais as perspectivas comparativas sobre em que medida essas diferenças de classe são (ou não são) replicadas em outras culturas. Para ter uma dimensão possível de comparação, um estudo sobre as atitudes da classe média em relação à televisão na Escandinávia (ver Alasuutari, 1999), mostra que também lá, os telespectadores frequentemente demonstram vergonha ao assistir um mero entretenimento, enquanto que o ato de assistir o noticiário nacional é comumente considerado como uma das principais responsabilidades de um bom cidadão. Em relação às atitudes da classe média em relação ao aparelho de televisão em si, as descobertas de Skeggs et al (2008) parecem coincidir tanto com as pesquisas sobre o constrangimento da classe média em ser apanhada assistindo televisão nos Estados Unidos da década de 1950, assim como com o trabalho histórico sobre os diferentes modos de esconder - ou mostrar - aparelhos de televisão entre a classe média e famílias da classe trabalhadora n América Latina (ver Leal, 1990 e Spigel, 1992). No entanto, precisamos observa de perto a importância simbólica de algumas tecnologias de comunicação em diferentes contextos e períodos. Nesse mesmo assunto, Nunn e Biressi oferecem uma atualização útil quando observam o que seria a ausência de uma televisão de tela plana hoje em dia, ao invés de simplesmente a ausência de um aparelho de televisão por si, o que seria um relevante índice de respeitabilidade (Nunn e Biressi, no prelo).

Para alguém preocupado com padrões de interpretação da televisão baseados em diferenciais de classe, a evidência de invocação dos inquiridos encontrada por Skeggs et al. de valores específicos da classe trabalhadora, como uma maneira de minar os discursos da classe média dominante da TR e seus representantes especialistas, é particularmente admirável em aumentar nosso entendimento do repertório do que poderia, em uma terminologia anterior, ter sido chamado de decodificações antagônicas (idem, 2008). No entanto, como argumentam os autores, ao invés de simplesmente serem vistas isoladamente, essas questões obviamente devem ser relacionadas às tradições mais antiga de articulação desses valores, tais como as do Victorian Music Hall ${ }^{8}$, que ainda fornecem uma parte crucial e formativa do repertório da cultura das classes trabalhadoras na qual se baseiam as respostas contemporâneas em relação à mídia (ver Clayton, 2008; Medhurst, 2007: cap. 5; Palmer, 1974 e Vicinus, 1974).

\section{HISTÓRIAS DE CLASSE E DE REPRESENTAÇÃO}

Peço permissão para ensaiar uma definição sobre essas preocupações específica e contemporâneas sobre a TR em vários contextos históricos.

\section{As classes entre a audiência da mídia}

No contexto dos debates sobre o problema de classe em estudos de audiência, atualmente presume-se que a tentativa de estabelecer conexões entre posição social e as modalidades de consumo midiático é sabidamente uma perd de tempo reducionista. Não obstante, como afirmei em outro trabalho, a análise de classe não necessita ser pré-estabelecida em nenhuma simples aritmética de determinação direta, na qual as respostas da audiência para os materiais da 
mídia seriam vistas como automaticamente determinadas pela posição de classe dessa audiência (Althusser, 1972; Laclau, 1977 e Morley, 1992). O que antes precisa ser explorado é como a posição estrutural, através de uma escala de dimensões (incluindo, mas não se restringindo à classe), pode definir parâmetros para a aquisição de diferentes códigos culturais, cuja posse pode então flexionar o processo de decodificação em modos sistematicamente diferentes (ver Kim, 2004, para uma análise crítica de debates sobre classe e decodificação).

Em uma época em que ouvimos que a própria classe não é mais do que uma categoria "zumbi" (ver Beck, 2008), essas questões obviamente adquirem maior pertinência. Em minha opinião, o problema não é tanto a questão ontológica sobre a existência dessas classes, mas a questão de como uma categoria como classe pode ser posicionada em nossas análises - a que nível de abstração, para quais fins e em relação a quais teorias de causalidade. Claramente, qualquer categoria sociológica, seja de classe, gênero, raça ou etnia, pode ser implementada de um modo zumbi. Essa é a principal força da crítica pós-estruturalista do essencialismo: daí as importantes críticas feitas por acadêmicos como Ien Ang e Joke Hermes (1991) e Ramaswami Harindrath (2005) para o trabalho que fez um curto-circuito na tarefa analítica de diversas tentativas de explicar as respostas da audiência ao material de mídia, como se essas respostas fossem um resultado ligado ao fato de as pessoas serem prisioneiras de categorias raciais, étnicas ou de gênero (ver também Butler, 1990).

É neste contexto que devemos considerar a crítica de Harindrath a vários estudos atuais sobre audiência, por falharem em "oferecer explanações suficientemente complexas de como fatores socioculturais influenciam as expectativas do público" (2005: 3, ênfase nossa). Sua maior preocupação é como as categorias de raça e etnia têm sido implementadas em estudos de audiência. Em especial, ele critica o modo como, em seu estudo hoje considerado canônico das decodificações diferenciais da audiência de Dallas, Tamar, Liebes e Elihu Katz (1991) se basearam no que Harindrath chama de "concepção monolítica de etnia [...] constituída por raça [...] [a qual] determina as decodificações da audiência" (2005: 5). Como ele observa, essa abordagem "privilegiando as diferenças culturais como imutáveis [...] [e] como uma categoria essencial” faz colapsar o conceito de raça dentro de cultura e naturaliza as diferenças sociais, como se esses fatores tivessem um efeito automático de definição de identidade e comportamento.

Este é um modelo no qual, ao invés da etnia exibir algum grau de mutabilidade na vida social, é reduzida ao status de uma categoria fixa pseudobiológica de um pertencimento automático, com efeitos aparentemente inevitáveis. É claro que, em termos conceituais, tal abordagem compartilha todas as desvantagens das formas mais simples da aritmética política marxista e, como uma ferramenta analítica, é muito crua para oferecer uma aquisição mais efetiva da vida sócio-cultural. No entanto, evidentemente, isso não significa que devemos abandonar o uso combinado das categorias raça e/ou etnia. Pelo contrário, o desafio é desenvolver versões mais matizadas e flexíveis de tais categorias, como foi evidenciado no trabalho de Stuart Hall sobre "novas etnicidades" (1988) ou no estudo de Paul Gilroy (2004) sobre as novas formas de racismo cultural. Portanto, como Kevin Robins e Asu Aksoy (2001) argumentam em seu estudo sobre o consumo de mídia por imigrantes turcos, devemos ser sensíveis às múltiplas dimensões de identidade das pessoas (étnicas e outras) e não presumir que alguma delas é necessariamente dominante em todas as situações. Essa abordagem foi mais bem desenvolvida no trabalho de Gerd Baumann (1996), que estuda como as pessoas se inspiram em diferentes registros de suas identidades, distintas dimensões étnicas, raciais, nacionais, religiosas (e outras) em diferentes contextos e em quais situações é mais provável que essas pessoas sintam essas dimensões mais relevantes e em quais contextos.

Entretanto, se essas categorias analíticas devem ser utilizadas criteriosamente, também devemos prestar atenção ao preço elevado de não usá-las por medo da acusação de essencialismo ou reducionismo - o que costumava ser denominado de individualismo metodológico. Desse modo, em relação ao gênero como um fator explanatório em estudos de mídia, críticos como Ang e Hermes (1991) têm toda a razão em argumentar que não podemos presumir a priori que, em qualquer instância específica de consumo de mídia, o fator determinante será necessariamente o gênero. No entanto, recusar-se a faze qualquer hipótese sobre quais fatores são mais prováveis de terem que tipo de consequência, e em quais situações, seria abandonar toda forma de análise social que, afinal, depende do uso de categorizações para poder se abstrair do detalhes e, assim, revelar padrões supraindividuais. Apesar das categorizações serem redutoras por natureza, a questão centra-se em decidir que tipo de dispositivos de categorização utilizar, mesmo que provisoriamente, ao analisar qual tipo de material. De outro modo ficamos flutuando em um jogo interminável de especificidade contextual e diferenças infinitas, no qual ao não fazermos nenhuma generalização, enfraquecemos nossas próprias análises.

No contexto dos debates sobre a autorreflexividade em antropologia, Clifford Geertz (1988) escreveu sobre os efeitos incapacitantes dos perigo daquilo que ele chama de "hermenêutica da suspeita". Eu acredito que nos últimos anos testemunhamos um fenômeno comparável ao nervosismo disseminado sobre o uso de categorias como classe em análise social. Curiosamente nesse contexto, encontramos uma contundente homologia entre o trabalho de 
teóricos contemporâneos da mídia, que estão relutantes em utilizar o conceito de classe como uma variável explanatória por medo de serem acusados de essencialismo, e os discursos da TR em si, que rotineiramente ignoram os fatores estruturais e apoiam-se em discursos de força de vontade voluntaristas, utilizando paixão e esforço como fatores determinantes do sucesso ou do fracasso individual.

\section{Linguagem, classe e os debates sobre privação cultural}

A segunda história que invocarei refere-se à ressonância contemporânea da obra de Basil Bernstein (1971) e Pierre Bourdieu (1984), que estudaram o papel da estrutura de classes, que distribui as formas de capital cultural, e de competência linguística de forma sistematicamente diferente e desigual. Apesar dos trabalhos de Bourdieu terem recebido bastante atenção no Reino Unido nos últimos anos (apesar das dificuldades de transposição dos seus resultados do contexto francês para o contexto britânico), os estudos de Bernstein têm sido bastante negligenciados, e são sobre estes trabalhos que desejo chamar a atenção aqui.

Para recapitular, o interesse de Bernstein era explicar o fracasso sistemático das crianças da classe trabalhadora nas escolas britânicas. Sua explicação, a grosso modo, foi que estas crianças não teriam as habilidades de raciocínio abstrato recompensados dentro do sistema educativo, e que isto estaria refletido na habilidade destas crianças para falar unicamente o que ele chamou de um código linguístico "restrito", que só permitiria poderes limitados de abstração. Esta "falta" inicial, argumentou Bernstein, foi o resultado das formas de socialização mais autoritárias características em famílias da classe trabalhadora.

Como esperado, o trabalho de Bernstein foi rapidamente atacado por aqueles que acreditavam ser bastante inapropriado fazer juízos de valor sobre o mérito relativo dos sistemas de fala e as culturas que estes sistemas simbolizam, sem fazer referência à imbricação destes nas estruturas de poder. Estudiosos como Harold Rosen (1972) argumentaram que a abordagem de Bernstein foi baseada na pressuposição de algum tipo de déficit cultural da classe trabalhadora. Em um espírito semelhante, Nell Keddie (1973) salientou que o problema com qualquer teoria de "privação cultural" era que nenhum grupo pode ser privado da sua própria cultura. Desse ponto de vista, a cultura da classe trabalhadora (ou a cultura negra; ver Labov, 1973, 2006) foi mostrada como tão valiosa como a cultura da classe média. E o insucesso escolar por parte da classe trabalhadora ou de crianças negras foi explicado pela desconexão entre a cultura desses alunos e a cultura da classe média/branca predominante nas escolas que frequentavam.
Outra linha de argumentação elaborada por Rosen (a qual, em muitos aspectos, previu o pós-estruturalismo contemporâneo) é a de que Bernstein teria utilizado classe como um simples dispositivo explanatório, na medida em que ele ignorou as muitas variedades da fala da classe trabalhadora, tanto as provenientes de subculturas regionais, ocupacionais ou institucionais - a questão sobre o que diferenciaria a linguagem de estivadores de Liverpoo daquela dos operários da indústria automobilística de Coventry, ou da linguagem de mineiros de Durham (Rosen, 1972). Claro que hoje no Reino Unido a terminologia é algo chocante, ao se referir, como o faz, para o que atualmente são apenas categorias mitológicas de trabalho, dada a subsequente dizimação dessas indústrias. Todavia, a questão do princípio de Rosen permanece e sua crítica da teoria generalizada de "privação cultural" ajudou a geração de projetos como o "People's Autobiography of Hackney", liderado por Ken Worpole na instituição Centerprise em East London ${ }^{10}$. Livros como Working Lives ${ }^{11}$ publicado pela própria Centerprise, baseavam-se na noção de que diferentes categorias de pessoas da classe trabalhadora não só tinham as suas própria histórias para contar, como também competência linguística para articular essas histórias em modos peculiares.

No entanto, mesmo se histórias da classe trabalhadora fossem agora contadas por pessoas da classe trabalhadora, os ativistas de classe média que o organizam seriam eles mesmos da classe média, na maioria das vezes (pelo menos em virtude da educação), e as relações de poder estariam obviamente em jogo. Eles são potencialmente vítimas da sanção foucaultiana contra a pressuposição de representar outros e da importância de todos falarem por si mesmos. A dificuldade dessa imposição é que ela logicamente implica uma regressão interminável, e em termos sociológicos, se apenas os membros da categoria $\mathrm{X}$ podem falar por essa categoria, as categorias em si têm uma rápida (e às veze surpreendente) capacidade de se fragmentar em subdivisões ainda menores. Esse é um caminho ao final do qual, evidentemente, só podemos chegar a um mundo de contabilidades separadas de microcoletividades de solipsismo experimental ou cultural.

Esse é um território nitidamente complexo. É interessante notar que no últimos anos, o acompanhamento metodológico da crítica teórica de essencialismo de classe tem sido, às vezes, a pressuposição de que apenas membro da classe trabalhadora (ou, em outra variante, somente estudiosos de origem da classe trabalhadora) poderiam ou deveriam falar (ou pesquisar) sobre essa experiência soberana. Contra essa posição, podemos apontar um contraexemplo óbvio, o extraordinário sucesso conseguido por Charles Parker em seus primeiros programas do show Radio Ballads ${ }^{12}$ (ver Cox, 2008), ao entrevistar pessoas
9. Vidas operárias populaçäa de Hackn Working lives - a people's autobiography of Hackn Association. Hackney Branch, Centerprise Trust:
Londres, 1976, 1977 (NT). 10. Éa região Leste, perto do Porto de Londres original. É conhecida pobres da cidade, com alta porcentagem de imigrantes em sua populaçăo (NT). 11. Vidas operárias ver nota 9 (NT).
12. Radio Ballads foi um
novo tipo de programa novo tipo de program
produzido na $\mathrm{BBC}$ por Charles Parker, Ewan MacColl e Peggy Seeger no final dos anos
cinquenta e início dos anos sessenta (NT). 
da classe trabalhadora e conseguindo que elas articulassem suas experiências, apesar dele possuir a indisfarçável voz e as maneiras de pessoas educadas em escola pública, sendo um ex-comandante de submarino como ele era. Esse fato poderia até sugerir que talvez, em termos metodológicos (e com certeza, políticos), contra as pressuposições do solipsismo cultural, mais importante que você ser de uma categoria social ou cultural diferente de seus entrevistados é como você vive essa diferença.

Por outro lado, permanece a dificuldade adicional de que, apesar da maioria do trabalho estimulado por organizações como a Federation of Worker Writers and Community Publishers ter sido extremamente valioso ao contar histórias de vidas anteriormente invisíveis e oferecer espaço para perspectivas culturais há muito tempo ignoradas (Morley e Worpole, 1986), ainda persiste um problema de configuração. De longe, a maneira mais fácil de consegui que a classe trabalhadora articule sua experiência é na forma de autobiografia, que é por natureza uma forma de individualização e, portanto, descoletivização - ou talvez despolitização. Com isso em mente, o projeto Centerprise tomou cuidadosamente o título de People's Autobiography of Hackney, apesar de constituído por relatos pessoais.

É nesse contexto que talvez seja mais bem compreendido o estudo de Diana Adlam e Angie Salfield (1980), em sua enérgica defesa de Bernstein contra seus críticos libertários. Simplificando, eles argumentam que, mesmo que a crítica de Rosen pudesse parecer politicamente atraente ao defender a cultura da classe trabalhadora, esta continua a encorajar uma forma que basicamente desabilita o relativismo cultural. Esse relativismo negaria o fato de que alguma formas de linguagem efetivamente permitem procedimentos conceituais mais complexos do que outros.

A crítica de Rosen ao trabalho de Bernstein pode ser mais bem compreendida na medida em que este último claramente falha ao expressar as muitas maneiras nas quais as competências linguísticas que as escolas estão preocupadas em desenvolver estão muitas vezes enredadas em formas culturais dominantes, que as tornam menos acessíveis aos filhos da classe trabalhadora (ou não-branca) (ver Labov, 1973, 2006). No entanto, uma defesa simplista da cultura da classe trabalhadora - por sua autenticidade, autonomia e espontaneidade - ainda convive com o problema de que esta cultura também possui limitações, não tanto de um ponto de vista político, mas de uma perspectiva educacional.

Em muitos aspectos, a posição de Bernstein pode ser vista como sustentada pela posição de Marx (ver Morley, 1974). Há certamente um paralelo entre o que Bernstein afirma sobre os limites do código linguístico restrito às classes trabalhadoras e o que Marx (e Lênin) diz sobre as limitações das formas espontâneas de consciência política. Suas críticas focam a incapacidade das parcela constituintes das classes trabalhadoras em atingir a consciência de classe ao abstraírem-se de sua situação local o suficiente para perceberem que realmente têm interesses em comum com pessoas que, em termos superficiais, parecen ser muito diferentes delas: gente que tem trabalhos diferentes, falam com outros sotaques, descendem de outras etnias e adoram outras divindades (ou nenhuma). Em cada caso, a dificuldade conceitual é a das limitações dos modo concretos de pensar, se não são acompanhados pela habilidade de abstração: transferir princípios e distinguir níveis superiores de categorização. Em resumo, essa é a capacidade para classificar a si mesmo e aos outros em categorias e utilizando os termos de Marx, de reconhecer a si mesmo, se for o caso, como membro de uma classe.

Em tudo isso, é importante observar o quão estão entrelaçadas as questões linguísticas, conceituais e políticas. Para fazer um paralelo literário, o romancista escocês James Kellman expressa caracteristicamente as lutas de pode presentes em seus romances através dos registros de linguagem utilizados por seus personagens. Desse modo, ele se recusa firmemente a acatar a convenção segundo a qual as formas regionais de dialeto ou o modo de falar da classe trabalhadora são normalmente utilizados apenas para o diálogo, enquanto o metadiscurso de narração autoral é reservado exclusivamente para a gramática e o vocabulário do inglês padrão. Como Ken Worpole observa em sua perceptiva discussão do trabalho de Kellman, quando essas relações são invertidas (pelo dispositivo verdadeiramente radical do uso de um dialeto e de um sotaque regional na metanarrativa de um texto, como uma "moldura" em torno de uma voz falando com "pronúncias recebidas"), percebemos imediatamente quão profundamente essas convenções estão arraigadas (Worpole, 2008: 31).

No entanto, o comprometimento de Kellman com a representação acurada da consciência interior e das vozes dos seus personagens da classe trabalhador possui seus próprios problemas, como Michel Faber observou na resenha de seu último romance, Kieron Smith, Boy ${ }^{13}$ (2008). Existiriam dificuldades inevitávei decorrentes da determinação do autor de pintar uma imagem autêntica de um mundo complexo e problemático do ponto de vista de uma criança da classe trabalhadora com um vocabulário muito restrito, falando com sua própria voz Isso aconteceria, ao menos, porque dadas as limitações linguísticas e conceituai de sua perspectiva, a criança tem apenas um entendimento muito estreito superficial do mundo que a rodeia. Kellman só consegue (se é que de modo fiel) representar a incapacidade da personagem para elaborar qualquer análise clara e coerente sobre o que está acontecendo com ela. Contudo, estas não são 
questões meramente de estilo literário, pois, como Volosinov (1973) argumenta, são nas formas de linguagem que a consciência toma forma - e as limitações da linguagem implicam, desse modo, limitações de consciência -, seja de classe ou de qualquer outra dimensão estrutural da vida social.

Em seus últimos anos, Derrida fez afirmações bastante interessantes sobre as maneiras pelas quais a teoria social ocidental ainda é assombrada pelo fantasma do marxismo, apesar de seu repúdio generalizado após a queda da União Soviética (Derrida, 2006). No contexto desses comentários, utilizarei, por último, outro contexto histórico, desta vez sobre os paralelos (e disjunções) entre algumas das coisas muito críticas que Marx teria dito sobre os antepassados fantasmagóricos das pessoas que hoje assistimos na TR e sobre as terminologias pelas quais seus descendentes são ridicularizados por suas inadequações.

\section{Maus cidadãos, os pobres indisciplinados e o lumpemproletariado} distingue a categoria lúmpen da categoria proletariado correto $^{14}$ são muito semelhantes aos utilizados na TR para fazer a distinção entre os pobres desregrados/ indisciplinados e os membros respeitáveis da sociedade. Marx teria sido tão desdenhoso como a TR poderia ser em suas caracterizações das pessoas nesta categoria problemática - a desprezível e irracional multidão que deve ser estritamente diferenciada da categoria das massas respeitáveis. Ele descreve essas pessoas de variadas formas, como "o proletariado da favela [...], os elementos da população submersa, os degenerados, e os párias [...], a putrefação passiva das camadas mais baixas da antiga sociedade [...], o refugo humano de todas as classes [...], trapaceiros, vigaristas, carroceiros, vadios, apostadores, criminosos, prostitutas e impostores". Portanto, é claro que para Marx, o termo lumpemproletariado é uma categoria moral ao invés de simplesmente uma categoria analítica ou econômica, e um pouco como ocorre com a TR, ele estava perfeitamente confortável em usar uma linguagem crítica para descrever o que considerava errado (e crucialmente para ele, politicamente incapacitante) em seu estilo de vida. ${ }^{15}$

Como várias pessoas já apontaram, os bad guys (e garotas) nesse cenário também nos parecem familiares pelos estereótipos em discursos como a caracterização da classe "destituída" feita por Charles Murray (desenvolvida inicialmente nos Estados Unidos e depois no Reino Unido; Murray, 1989). Quando eu estava navegando pela internet procurando material sobre essas questões, encontrei um site no qual um acadêmico americano tentava oferecer uma ajuda mnemônica visual para que seus alunos entendessem a diferença entre essas categorias. Uma das dicas que ele deu foi a seguinte: "se o proletariado é um
Em primeiro lugar, vale a pena observar que os critérios pelos quais Marx atleta jovem, bonito, musculoso, com um andar elegante, uma postura ereta e bons dentes, o lúmpen é um rapaz magro e desleixado com o olhar esquivo e um cigarro pendendo dos lábios". ${ }^{16}$ Nesse momento, eu senti como se eu já tivesse visto aquele segmento de edição com técnicas de rrosscut $^{17}$ na própria TR. Certamente, essas pessoas são então definidas como tendo vários tipos de graves falhas morais. Além disso, se uma dimensão do problema representado pelos pobres displicentes na TR reside na incapacidade dos mesmos de serem devidamente produtivos, o seu aspecto complementar é representado por discussões sobre a cultura chav, cujas disposições patológicas são mostradas não só no fracasso de se empregar em formas legítimas de trabalho produtivo, ma também na esfera do consumo na medida em que este grupo é visto consumindo coisas erradas de forma errada (ver Hayward e Yard, 2006).

Todavia, existem duas diferenças fundamentais entre a perspectiva de Marx sobre essas questões e a perspectiva da TR: a primeira, a definição do problema (e qual poderia ser sua solução), e a segunda, as suas causas e origens. Para lidar com a primeira delas, se o problema para a TR é de que os pobres e o vários tipos de pessoas infelizes que ela representa falham em ser o tipo certo de indivíduos, o problema de Marx é o oposto. Para ele, o fracasso dessas pessoas reside no fato delas somente serem capazes de se comportar como indivíduos, falhando em superar a preocupação com os seus próprios interesses imediato de curto prazo, para poderem agir como uma classe. É por isso que Marx os considera um grupo não confiável politicamente (e realmente "perigoso") que ao ser "jogado para lá e para cá por acontecimentos", é particularmente vulnerável a discursos reacionários e é efetivamente capaz de ser "subornado" por qualquer um que puder lhe oferecer um benefício imediato suficiente para ajudá-lo a sobreviver mais um dia.

Aqui é onde também emerge o segundo contraste. Ao contrário do discurso da TR, que faz os indivíduos inteiramente responsáveis por seus próprio destinos, Marx é muito claro que são as condições de existência do lumpemproletariado, sob as quais (em virtude da falta de alternativa econômica desses indivíduos) eles são condenados a escarvar por aí, tentando sobreviver ao cotidiano, que os tornam incapazes de fazer outra coisa senão pensar em suas preocupações imediatas de curto prazo.

Em um momento chave, quando Marx define os vários segmentos do lumpemproletariado, ele identifica como um grupo particularmente importante, antes "útil", mas agora desempregado, que não tem nenhuma relação segura ou interesse, com o sistema de produção. Essa é, com efeito, uma categoria de indivíduos a quem se tem compaixão (páthos), em virtude do seu desemprego Aqui encontramos o que talvez seja a chave da sua abordagem. Para Marx
16. Para checar a fonte dessas imagens impressionanedu/polisci/faculty/ander-

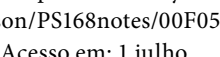
(Acesso em: 1 julho
2009). Ver também os contundentes comentários de John Berger sobre como os mercados financeirose as favelas "têm uma cois em comum: o ruído do
boato" (Berger, 1996: 7) 17. Técnica de ediçăo 
a degeneração do lumpemproletariado aparece precisamente por sua posição deslocada, como um elemento de "população excedente", sem nenhuma função econômica regular. Isso, segundo ele, é o que torna esses indivíduos suscetíveis a "agentes de corrupção", e quanto mais ficarem fora do processo produtivo, mais provável é que acabem adotando atitudes "degeneradas".

Na época de Marx, essa era uma categoria marginal e relativamente peque- na de pessoas que ainda não tinham se ajustado ao novo sistema de produção industrial, mas tinham ainda esperança de um dia voltar a se reintroduzir no chamado proletariado correto. No entanto, depois do colapso das indústrias manufatureiras que costumavam oferecer trabalhos manuais para a maioria população excedente é cada vez mais frequente nas economias avançadas do Ocidente. Agora, ao invés de ser apenas uma categoria marginal, essa é a situação da grande maioria do que já foi um dia o dito proletariado respeitável.

Se essa transformação na escala da categoria dos indivíduos não-empregáveis constitui uma mudança fundamental nas circunstâncias que envolvem as classes mais baixas, existem também dificuldades a serem exploradas relativas às relações de classe e cultura e do potencial, em algumas circunstâncias, de surpreendentes modos de alianças entre classes (ver Laclau, 1977, sobre o peronismo). Do ponto de vista de Marx, o lumpemproletariado tem a peculiaridade de compartilhar algumas características com a categoria chamada de "capital financeiro", e ele analisa várias situações nas quais essas categorias se tornariam aliados políticos (ver Hayes, 1988, 1992). Visivelmente, as duas categorias não compartilham interesses materiais em nenhum sentido, na verdade, o que as conecta é que são "improdutivas" em termos marxistas, na medida em que ambas estão localizadas fora do sistema de produção. E realmente em um momento, Marx fala do capital financeiro como o "renascimento do lumpemproletariado nos cumes da sociedade burguesa". 18

Essas correspondências têm um significado ainda maior. Não foram só os problemas do lumpemproletariado que se deslocaram das margens para o palco uma categoria meramente suplementar da produção manufatureira, hoje em dia vivemos em uma era da financeirização da economia mundial, onde o próprio capital financeiro fornece a principal forma de atividade econômica (especialmente no Reino Unido desde o boom no setor financeiro, uma consequência da desregulamentação no City trading ${ }^{19}$ na década de 1980). Contudo, é importante relembrar que por mais complexa que seja a estrutura dos derivados financeiros em que esses negócios comerciam, eles ainda são, no final, simplesmente uma forma superior de aposta. ${ }^{20}$ dos indivíduos pouco qualificados da classe trabalhadora, essa categoria de central no mundo contemporâneo. Se na época de Marx o capital financeiro era
Se relacionarmos essa faceta do capital financeiro com a cultura da loteria que agora se tornou tão importante na sociedade britânica, podemos identifica um conjunto central de valores que focam na propensão que o mercado teria de distribuir os seus favores aleatoriamente, quer na forma de riqueza ou de celebridade. Nesse contexto, como um editorial do jornal Guardian colocou, "a esperança [agora] reside na possibilidade de nós também sermos apanhados nesse tipo de exaltações imprevisíveis - acreditar que o bilhete premiado pode ser o nosso, ou o número da sorte, o grande prêmio, ou que o talento excepcional [das nossas crianças] as levará flutuando ao estrelato, trazendo muito mais riquezas do que alguma vez sonharam (Richly Undeserved ${ }^{21}$ Guardian, 13 de maio de 2008). Por causa disso, qualquer ideia de um projeto coletivo para obter um aprimoramento (ou uma verdadeira transformação) das condições sociais para todos através de uma política de esperança, é então trocada por uma confiança fatalista em alguma fada da sorte fazendo alguma beneficência aleatória com os indivíduos, ou, na melhor das hipóteses, a favor dos indivíduos lutando por seu próprio sucesso através de sua própria pura paixão ou compromisso, apesar de suas terríveis circunstâncias.

Para colocar o assunto em um contexto mais amplo, a questão-chave aqu não é simplesmente a inadequação da representação da classe trabalhador na TR, mas sim a sua total inabilidade para representar o universo do social. Nesse sentido, esses discursos dos programas poderiam ser simplesmente lido como uma instanciação televisual do credo da senhora Thatcher de que não existe tal coisa como sociedade, mas apenas indivíduos, homens e mulheres; esses discursos simplesmente seguem os caminhos sombrios traçados pela desvalorização radical de qualquer entendimento sociológico do mundo.

CONCLUSÃO: REPRESENTANDO AQUELES QUE SÃO SHAMELESS. Como conclusão a estas considerações, retornarei a um exemplo ilustrativo contemporâneo dessas questões nos debates de Paul Abbott sobre a representação atual do lumpemproletariado no bairro ficcional de Manchester, Chatsworth Estate na série televisiva do Channel 4, Shameless. ${ }^{22}$ Abbott trabalhou muito anos na novela Coronation Street, da emissora ITV, e depois como produto de séries como Cracker, de Jimmy McGovern. Primeiramente veiculada no Channel 4, em 2004, a série Shameless foi posteriormente transmitida no Estados Unidos, Austrália, Canadá, Holanda, Portugal, Itália e Finlândia.

A série era centrada na vida caótica dos membros da família disfuncional chamada Gallagher, supostamente chefiada por um pai desempregado alcoólatra, em que as crianças são deixadas muitas vezes à própria sorte, em um estado exaurido de uma vida selvagem, de pobreza limítrofe da classe trabalhadora.
21. Ricos sem mérito (NT).

2. O verbete de Shameless boa historia daerece uma contextualiza a série e suas ambiç̧̄es em uma visão mais ampla do drama na
televiša britânica (http:// levisaá britânica (http:// wiki/Shameless). Um outro exemplo ilustrativo seria o trabalho de um escritor como Jimmy McGovern, original mente ligado a
uma filial de Liverpool da Federation of Worker Writers and Community Publishers, e que depois se tornou um escritor bem-
sucedido da novela sobre vida da classe trabalhadora, Brookside (1982), veiculada no Channel 4 , se guida de séries dramáticas mostrando personagens
da classe trabalhadora, transmitidas em horário nobre, incluindo Cracker (1993), Hillsborough (1996), The Lakes (1997
1999), Sunday (2002) The Street (2006 a 2009). 
Apesar das circunstâncias calamitosas em que vivem, a característica potencialmente redentora é a maneira pela qual, apesar de seus momentos de desconsideração e crueldade, esses indivíduos se unem por meio de ligações densas e estreitas, ligados por laços de sangue e de lealdade. Muitos aspectos da série recriam o ambiente das experiências da própria infância de Abbott em uma vizinhança similar, Bury, na qual, como ele mesmo disse em uma entrevista, "o caos era a norma", ao lado da pobreza e da criminalidade, em uma vida caracterizada por "pais ausentes, gravidez na adolescência, falta de rendimentos legítimos, e cercados pela expectativa de sentenças penais". Hoje, Abbott percebe que a situação só era tolerável pelo simples fato de que "nós não tínhamos nenhuma ideia de que as coisas poderiam ou deveriam ser um pouco melhores".

Como Jennings (2008) observa, a série se recusa a centrar a sua narrativa em em: www.channelt. m/entertainment/ $/$

de problemas ou questões supostamente objetivas, ao invés disso o foco sobre "a determinação da família para sobreviver em conjunto e poder manter um sentido (ou uma ilusão) de ação e esperança". Abbott afirmou que ele "aderiu ao título da série por sua ironia, porque era exatamente o tipo de acusação que as pessoas de fora teriam feito à minha família no período dos anos setenta" (entrevista com Paul Abbott no jornal Independent, 20 de dezembro de 2005).

Shameless foi descrita por um crítico como "a série que o bom gosto esqueceu" e pelo seu ator principal, David Threlfall, como "os Simpsons sob efeito de acido lisérgico" (Independent, 20 de dezembro de 2005). É um programa desconfortável de assistir, fazendo uma guinada deliberada entre os gêneros drama e sitcom, misturando melodrama e excesso com os aspectos mais sombrios do realismo social (Nelson, 2007: 45-48) e, ao mesmo tempo, tentando ser, nas palavras do próprio Abbott, "desconcertante e engraçada ao mesmo tempo" (entrevista com Stuart Jeffries, Guardian, 7 de fevereiro de 2005). A série também é feita de tal forma que a torna particularmente desconfortável aos telespectadores respeitáveis da classe média, envolvendo-os na vida de pessoas que eles nunca encontrariam em seus próprios bairros, desafiando as suposições convencionais sobre o que constitui a normalidade e a moralidade. Para Threlfall, seu propósito é muito sério e ele o descreve como "o perfeito drama da contração de crédito [...] que retrata uma família que é o epítome de como você contorna tempos difíceis" (Sunday Telegraph, 25 de janeiro de 2009).

Muitos dos aspectos formais da série acima mencionada têm recebido elogios, assim como as suas ambiciosas tentativas de misturar regras genéricas em um modo de apresentação que gira entre o surrealismo sarjeta, violência de história em quadrinhos ${ }^{24}$ e humor negro (Jennings, 2008; Nelson, 2007). Esta originalidade formal significa que muitas vezes a série confunde as expectativas dos telespectadores. Porém, vários críticos têm apontado como deliberadamente amoral (se não exploradora) a representação do comportamento bizarro dos personagens e das famílias disfuncionais feita por Abbott.

$\mathrm{Eu}$, no entanto, argumentaria que Shameless desempenha uma função muito valiosa ao inverter a perspectiva moralizante da TR e ao nos encoraja exatamente a desenvolver empatia com os problemas de maus sujeitos ${ }^{25}$ que falharam em adotar as maneiras de melhorar a si mesmos, condição exigid para o bom funcionamento do mercado liberal capitalista. Quanto à questão da moralidade em si, o principal ponto levantado pela série talvez não seja a atitude que devemos tomar em relação ao comportamento dessas personagens, mas sim à situação que as pressiona agir como agem. A clara implicação do metadiscurso do programa é que não é tanto o comportamento das própria personagens que merece o nosso opróbrio moral, mas sim as forças estruturais que as encarceraram nessa situação. Nessa história, os verdadeiros vilões são os responsáveis pela liquidação de bens ativos da indústria manufatureira do Reino Unido e a subsequente desindustrialização de regiões inteiras, resultando na devastação de lugares como Chatsworth Estate pelo longo tempo de desemprego durante várias gerações.

Muitos dos personagens são apresentados como sendo "profundamente nfelizes sobre muitas coisas, a maior parte do tempo", mas já que "este é um modo de ser totalmente familiar a eles, não há razão para que se preocupem ou se exasperem por isso". A série apresenta o fatalismo pragmático como a única política sensata disponível a essas pessoas (Jennings, 2008). E assim, um pouco como o lumpemproletariado na análise de Marx, ao estarem preocupadas com as necessidades em curto prazo da sobrevivência diária, essas personagens não articulam pontos de vista políticos explícitos e têm como objetivo principa simplesmente conseguir viver mais um dia e, de preferência, dando risada pelo caminho.

No mundo fictício de Shameless, a pobreza, a criminalidade e o caos são a norma, em relação à qual a única atitude que faz sentido é o mundo desencantado dos malandros de rua, acompanhada por uma incansável capacidade para improvisar estratégias de sobrevivência. Particularmente no início da série, antes que as personagens tivessem se estabelecido em suas modalidades mais caricaturais, a face mais aventureira em Shameless er essa normalização descarada da vida em tal situação, o que para as pessoa de fora poderia parecer anômalo (e de fato verdadeiramente chocante). O avanço narrativo mais categórico é a maneira pela qual esse estilo de vida cotidiano medonho, por demais evidente, é constituído como uma premissa não dita, subentendida na totalidade da série. A meu ver, essa série, na sua 
concepção, pelo menos, merece grande crédito por nos encorajar a pensar em formas mais complexas sobre a representação de classe na televisão. Não menos importante tem sido o fato de forçar uma representação convincente nas telas das televisões do Reino Unido de como é a vida de muitos que ainda sofrem, apesar de que bastante invisível aos olhos do público, a totalidade das consequências do que agora são trinta anos de hegemonia thatcherista, apesar de todas as mudanças nominais de governo.

Ao tentar navegar através dessas águas agitadas, é evidente que devemos desenvolver modelos mais incisivos de análise da representação feita pela televisão de grupos vulneráveis, sem poder ou influência social. Como sempre, se quisermos oferecer críticas dessas representações que supomos inadequadas, então também compete a nós - por mais difícil que seja - explicitar o que exatamente consideramos como uma boa forma de representação (ou pelo menos uma melhor) e esclarecer as bases nas quais fundamentamos nossas reivindicações. Evidentemente, isso vai nos levar para águas profundas, nas quais não chegaremos facilmente a um acordo em nossa tentativa de ir além da crítica limitada à especificação dos critérios para julgar essas complexas questões filosóficas e epistemológicas. Apesar disso, são questões das quais não podemos nos dar ao luxo de evitar se queremos ser capazes de observar não só como os debates contemporâneos sobre a TR se ajustam nas perspectivas históricas de longo prazo sobre a representação de classe, mas também como intervir eficazmente nesses debates.

\section{REFERÊNCIAS BIBLIOGRÁFICAS}

ADLAM, Diane e SALFIELD, Angie. The Diversion of Language: A Critical Assessment of the Concept of Linguistic Diversity, Screen Education, 34, pp. 71-86, 1980 ALASUUTARI, Pertti (ed.). Rethinking the Media Audience. Londres: Sage, 1999. ALTHUSSER, Louis. For Marx. Harmondsworth: Penguin, 1971

Ideology and Ideological State Apparatuses. In: Lenin and Philosophy. Londres: New Left Books, pp. 127-86, 1972.

ANG, Ien e HERMES, Joke. Gender and/in Media Consumption. In CUR RAN, James GUREVITCH, Michael (eds). Mass Media and Society. Londres: Edward Arnold, pp. 307-28, 1991.

BALEN, Malcolm. A Very English Deceit: The Secret History of the South Sea Bubble and the First Great Financial Scandal. Londres: Fourth Estate, 2002.

BAUMANN, Gerd. Contesting Culture: Discourses of Identity in Multi-ethnic London. Cambridge: Cambridge University Press, 1996.

BECK, Ulrich. World at Risk. Cambridge: Polity Press, 2008. e BECK-GERNSHEIN, Elisabeth. Individualization. Londres: Sage, 2002 BERGER, John. Rumour. In: TEKIN, Latife. Berji Kristin - Tales From the Garbage Hills. Londres: Marion Boyars, 1996.

BERnSTeIn, Basil. Class, Codes and Control, Vol. 1. Londres: Paladin, 1971.

BIRESSI, Anita. e NUNN, Heather. Reality Television: Realism and Revelation. Londres: Wallflower Press, 2005.

Bad Citizens: The Class Politics of Lifestyle Television. In: PALMER, Gareth

(ed.). Exposing Lifestyle Television. Londres: Ashgate, pp. 15-24, 2008. BOURDIEU, Pierre. Distinction. Londres: Routledge, 1984.

BOVENKERK, Frank. The Rehabilitation of the Rabble: How and Why Marx and Engels Wrongly Depicted the Lumpenproletariat as a Reactionary Force. In Netherlands Journal of Social Science 20 (1), pp. 13-42, 1984.

BRUNSDON, Charlotte. Is Television Studies History?, Cinema 47(3), pp.127-37, 2008 BUTLER, Judith. Gender Trouble. Londres: Routledge, 1990.

CLAYTON, Ian. Bringing it All BacK Home. Pontefract: Route Books, 2008.

CORNER, John. Television Studies: Plural Contexts, Singular Ambitions?.Journal of British Cinema and Television 1(1), pp 6-13, 2004.

COULDRY, N. Reality TV, or the Secret Theatre of Neoliberalism. In: Review of Education, Pedagogy and Cultural Studies 30(1), pp. 3-13, 2008.

Cox, Peter. Set into Song: Ewan MacColl, Charles Parker, Peggy Seeger and the Radio Ballads. London: Labatie Books, 2008.

DER RIDA, Jacques. Spectres of Marx. Londres: Routledge, 2006.

FABER, Michael. This Boy's Life. Guardian Saturday Review (26 de abril, 2008) Disponível em: www.guardian.co.uk/books/20o8/apr/26/featuresreviews.guardianreview28. Acesso em 1 de setembro 2009.

FISH, Stanley. The Young and the Restless. In: VEeSER, H. Aram, (ed.). The New Historicism. Londres: Routledge, pp. 303-16, 1989

GEERTZ, Clifford. Works and Lives: The Anthropologist as Author. Cambridge: Polity Press, 1988.

GERAGHTy, Christine. Critical Vocabularies and Popular Television Drama. In CURRAN, James e MORLEY, David (eds). Media and Cultural Theory, Londres: Routledge, pp. 221-32, 2006

GILROY, Paul. Between Camps: Nations, Cultures and the Allure of Race. Londres: Allen Lane, 2000.

GRAMSCI, Antonio. The Prison Notebooks. Londres: Lawrence \& Wishart, 1974.

HALL, Stuart. New Ethnicities. In: MERCER, Kobena (ed.) Black Film, British Cinema. British Film Institute/Institute of Contemporary Arts Documents $\mathrm{N}^{\circ}$ 7, pp. 27-31. London: Institute of Contemporary Arts, 1988 
Class-ificações Mediadas: Representações de classe e cultura

na televisão britânica contemporânea

HARINDRANATH, Ramaswami. Ethnicity and Cultural Difference: Some Thematic and Political Issues on Global Audience Research. In: Particip@tions. 2(2), 2005. Disponivel em: www.participations.org/volume 202/issue 202/2_02_harindranath. $\mathrm{htm}$. Acesso em 1 de setembro 2009.

HAYES, Peter. Utopia and the Lumpenproletariat: Marx's Reasoning in the $18^{\text {th }}$ Brumaire. Review of Politics 50(3), pp. 445-65, 1988.

. The People and the Mob. Londres: Praeger, 1992.

HAYWARD, Keith e YARD, Majid. The "Chav" Phenomenon: Consumption,

Media and the Construction of a New Underclass. In: Crime, Media and Culture, 2(1), 9-28, 2006.

JENNINGS, Tom. Shameless by Paul Abbott: Television Review, 2008. Disponivel em: http://libcom.org/library/shameless-paul-abbott-series-1-2-channel-420034-television. Acesso em: 8 de agosto, 2008.

KEDDIE, Nell. (ed.). Tinker, Tailor: The Myth of Cultural Deprivation. Harmondsworth: Penguin, 1973.

KELLMAN, James. Kieron Smith, Boy. Londres: Hamish Hamilton, 2008.

KIM, Sujeong. Re-reading David Morley's “The Nationwide Audience”. Cultural Studies 18(1), pp. 84-108, 2004.

LABOV, William. The Logic of Non-standard English. In: KEDDIE, Nell. (ed.). Tinker Tailor: The Myth of Cultural Deprivation. Harmondsworth: Penguin. pp. 21-67, 1973. . The Social Stratification of English in New York City. Cambridge: Cambridge University Press, 2006

LACLAU, Ernesto. Politics and Ideology. Londres: New Left Books, 1977.

LEAL, Ondina F. Popular Taste and Erudite Repertoire: The Place and Space of TV in Brazil. Cultural Studies 4(1), pp. 19-29, 1990.

LIEBES, Tamar e KATZ, Elihu. The Export of Meaning. Oxford: Oxford University Press, 1991.

MEDHURST, Andy. If Anywhere: Class Identifications and Cultural Studies Academics. In MUNT, Sally (ed.). Cultural Studies and the Working Class. Londres: Cassell, pp.19-35, 2000

. A National Joke. London: Routledge, 2007.

MORIN, Edgar e ROUCH, Jean. Chronique D'un Ete. Paris: Inter Spectacles, 1960.

MORLEY, David. Reconceptualising the Media Audience. CCCS, University of Birmingham, Occasional Paper, 1974.

. Television, Audiences and Cultural Studies. Londres: Routledge, 1992.

e WOR POLE, Ken. (eds). The Republic of Letters: Working Class Writing and Local Publishing. London: Comedia, 1982. (Uma segunda edição será lançada em 2010).
MUNT, Sally. (ed.) Cultural Studies and the Working Class. London: Cassell, 2000.

MURRAY, Charles. The Emerging British Underclass. In: LISTER, Ruth (ed.).

Charles Murray and the Underclass. Londres: IEA Health and Welfare Unit, pp 23-56, 1989 .

NELSON, Robin. State of Play: Contemporary "High-end" TV Drama. Manchester: Manchester University Press, 2007.

NUNN, Heather e BIRESSI, Anita. Reflections on the "Undeserving Poor" (inédito).

PALMER, G. "The New You: Class and Transformation in Lifestyle Programming". In HOLMES, Su e JERMYN, Deborah (eds). Understanding Reality Television. London: Routledge, pp 173-90, 2004.

PALMER, Roy. A Touch on the Times: Songs of Social Change, 1770-1914. Harmondsworth: Penguin, 1974 .

PARSONS, Talcott. The Social System. New York: Free Press, 1964.

ROBINS, Kevin e AKsOY, Asu. From Spaces of Identity to Mental Spaces:Lesson from Turkish-Cypriot Cultural Experiences in Britain. In: Journal of Ethnic and Migration Studies 27(4), pp 685-711, 2001.

ROSE, Nikolas. Governing the Soul: The Shaping of the Private Self. Londres: Routledge, 1989.

ROSEN, Harold. Language and Class. Bristol: Falling Wall Press, 1972.

SKEGGS, Bev. Formations of Class and Gender: Becoming Respectable. Londres: Sage, 1997.

Class, Self, Culture. London: Routledge, 2004.

- wOOD, Helen e THUMIM, Nancy. Oh Goodness, I Am Watching Reality TV How Methods Make Class in Audience Research. European Journal of Cultural Studies 11(1), pp. 5-24, 2008.

SPIGEL, Lynn. Make Room for TV. Chicago, IL: Chicago University Press, 1992

. "Introduction". In: SPIGEL, Lynn e OLSSON, Jan (eds). Television after TV.

Durham, NC: Duke University Press, pp. 1-40, 2004.

THOMPSON, Edward P. Time, Work-discipline and Industrial Capitalism. Past and Present 38, pp. 56-97, 1967.

VICINUS, Martha. The Industrial Muse. Londres: Croom Helm, 1974

voLOSINOV, Valentin. Marxism and the Philosophy of Language. Nova York: Academi Press, 1973.

WATSON, Paul (director). The Family. Broadcast on BBC, 1974.

WEARING, Gillian. Family History. Birmingham: Ikon Gallery, 2006.

WINSTON, Brian. Rouch's “Second Legacy": Chronique D'un Ete as Reality TV's Totemic Ancestor. In: BRINK, Joram Ten. (ed.) Building Bridges: The Cinema of Jean Rouch. Wallflower Press, pp. 297-311, 2007. 


\section{Class-ificações Mediadas: Representações de classe e cultura na televisão britânica contemporânea}

WOOD, Hellen e SKEGGS, Bev. Spectacular Morality: Reality TV, Individualisation and the Re-making of the Working Class. In: D. HESMONDHALGH, David e TOYNBEE, Jason (eds). The Media and Social Theory. Londres: Routledge, pp. 177-91, 2008.

WORPOLE, Ken. Dockers and Detectives (2da ed.). Nottingham: Five Leaves Publications, 2008.

Artigo traduZido do inglês por Silvia Cobelo

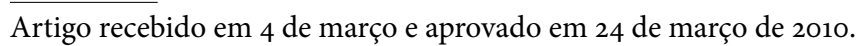

